\title{
Application of Distributed Optical Fiber Sensing Technique in Monitoring the Ground Deformation
}

\author{
Jin Liu, ${ }^{1}$ Yong Wang, ${ }^{1}$ Yi Lu, ${ }^{2}$ Jihong Wei, ${ }^{1}$ and Debi Prasanna Kanungo ${ }^{3}$ \\ ${ }^{1}$ School of Earth Sciences and Engineering, Hohai University, Nanjing 210098, China \\ ${ }^{2}$ Key Laboratory of Earth Fissures Geological Disaster, Ministry of Land and Resources, Geological Survey of Jiangsu Province, \\ Nanjing 210049, China \\ ${ }^{3}$ CSIR-Central Building Research Institute (CBRI), Roorkee 247667, India
}

Correspondence should be addressed to Jin Liu; jinliu920@163.com

Received 19 February 2017; Revised 23 March 2017; Accepted 2 April 2017; Published 9 April 2017

Academic Editor: Romeo Bernini

Copyright (C) 2017 Jin Liu et al. This is an open access article distributed under the Creative Commons Attribution License, which permits unrestricted use, distribution, and reproduction in any medium, provided the original work is properly cited.

The monitoring of ground deformation is important for the prevention and control of geological disaster including land subsidence, ground fissure, surface collapse, and landslides. In this study, a distributed optical fiber sensing technique based on Brillouin Optical Time-Domain Analysis (BOTDA) was used to monitor the ground deformation. The principle behind the BOTDA is first introduced, and then laboratory calibration test and physical model test were carried out. Finally, BOTDA-based monitoring of ground fissure was carried out in a test site. Experimental results show that the distributed optical fiber can measure the soil strain during ground deformation process, and the strain curve responded to the soil compression and tension region clearly. During field test in Wuxi City, China, the ground fissures deformation area was monitored accurately and the trend of deformation can also be achieved to forecast and warn against the ground fissure hazards.

\section{Introduction}

Ground deformation including land subsidence, ground fissure, and surface collapse is a serious geological disaster. The monitoring of ground deformation is therefore important for its prevention and control. This is also an effective way of reducing the risk due to ground deformation by developing early warning systems. The conventional technologies such as tiltmeters, inclinometers, and multipoint extensometers have been in practice for decades. The high cost and other problems associated with transmitting signals electrically make an automated system rather impractical for long term and massive deployment. Fiber Bragg Grating (FBG) as a sensing medium also has been used to develop the ground movement monitoring device $[1,2]$. The material and method of signal transmission of FBG are favorable for field geotechnical applications. But, due to their discrete point monitoring, it is very difficult to provide a continuous ground deformation in the complex geological environment. The vertical control network based on Global Positioning System (GPS) also was used to monitor ground deformation for decades [3-5]. This system can collect data automatically to provide large area of ground deformation, but, also, its results are easily affected by the buildings and crops on surface. Therefore, a new method with its advantages of direct embedding, distributed monitoring, automatic data collection, good durability, and high precision is needed to monitor the ground deformation.

The distributed optical fiber sensing technologies based on Brillouin Optical Time-Domain Analysis (BOTDA), Brillouin Optical Time-Domain Reflectometry (BOTDR), and Brillouin Optical Frequency-Domain Analysis (BOFDA) have been developed and used in geotechnical monitoring. The distributed optical fiber sensor based on BOTDA is installed into concrete to monitor actual strain in structures to provide an early warning of possible distress during the whole life of structures [6-9]. The distributed optical fiber sensing technique also was used to evaluate the mechanical behavior of pile during driving process $[10,11]$. These researches show that the distributed optical fiber sensing 
technique possesses the advantages of distributed monitoring, direct embedding, automatic data collection, good durability, and high precision to meet the requirement of ground deformation monitoring. Furthermore, the soil-embedded optical fiber has been used to monitor the deformation of slope and various special optical fibers can be developed to meet the requirement including larger deformation and coordination deformation [12-14]. Therefore, the distributed optical fiber sensing technique will provide a new effective method to monitor the ground deformation.

In this study, the distributed optical fiber sensing technique based on Brillouin Optical Time-Domain Analysis (BOTDA) was considered to monitor the ground deformation. The principle behind the BOTDA is introduced, and laboratory calibration test and physical model test were carried out. Finally, BOTDA-based monitoring of ground fissure was done in a field site in Wuxi City, China.

\section{Principle of BOTDA}

BOTDA is proposed for the measurement of light frequency distribution generated by Brillouin scattering effect, which is stimulated as the frequency difference between continuous wave light and pump pulse light propagating in optical fiber sensors which matches the local Brillouin frequency of fiber core. The basic principle of BOTDA is shown in Figure 1. Stimulated Brillouin Scattering (SBS) in optical fibers is coupled with the light among two counterpropagating light waves through an acoustooptical process. SBS is manifested by inducing counterpropagating frequency-shifted narrowband amplification and attenuation processes at frequencies, respectively. This Brillouin frequency shift (BFS) experiences a linear dependence on strain and temperature. This dependence of the BFS makes SBS suitable for distributed sensing, thus enabling a sensing system that can provide a longitudinal profile of these physical quantities. A distributed profile of the BFS evolution along the fiber is obtained, and consequently any local temperature or strain variation can be detected in the fiber.

BOTDA NBX-6050A developed by Japanese Neubrex Company was used in this study (see Figure 2). It is capable of measuring the strain value at any points distributed along the optical fiber from two ends of the sensing fiber continuously and simultaneously. The measured strain range is $\pm 3 \%$, the measurement accuracy is up to $\pm 7.5 \mu \varepsilon$, and the maximum distance reaches $1 \mathrm{~km}$. The spatial resolution set for strain measurements in the lab and in the field are $0.05 \mathrm{~m}$ and $0.1 \mathrm{~m}$, respectively.

\section{Laboratory Calibration Test}

In order to understand the monitoring effect of special optical fiber sensor under the different tension stress, a laboratory calibration test was carried out and the performance and analytical error of this distributed sensing technology were studied.

3.1. Experimental Program. In this experiment, the tensile stand was selected. This tensile stand has the functions of adjustable constraint distance, high-precision measurement and controlled tension force (Figure 3). Firstly, the ends of optical fiber were fixed in the tensile testing apparatus with a spacing of $5 \mathrm{~m}$ (see Figure 4). After checking the tensile testing apparatus, the initial data was measured as the reference value and the micrometer used in testing the tension amount was reset.

The strain was applied progressively during the testing process and the amount of tension was obtained by the micrometer. When the micrometer readings in two consecutive 15 minutes were less than the amount of deformation $0.01 \mathrm{~mm}$, the strain was determined to be the present level stretching end. The data acquisition of optical fiber strain value was recorded by BOTDA, and the actual strain shown in micrometer was obtained to be the reference data.

3.2. Test Results. The strain during the testing of optical fiber with the BOTDA can be obtained by

$$
\Delta L=\int_{Z_{1}}^{Z_{2}} \varepsilon(z) d z .
$$

In formula (1), $\Delta L$ is a length of optical fiber in the amount of compression or tension between $Z_{1}$ and $Z_{2}$ and $\varepsilon(z)$ is the value of each sampling strain interval between points $Z_{1}$ to $Z_{2}$, based on different monitoring requirements. There are the following sampling intervals: $1 \mathrm{~m}, 0.5 \mathrm{~m}, 0.2 \mathrm{~m}, 0.1 \mathrm{~m}$, and $0.05 \mathrm{~m}$. Column is set at sampling interval of $0.1 \mathrm{~m}$ and, hence, the sensing fiber of $1 \mathrm{~m}$ has 10 sampling points.

Optical fiber strain curves based on BOTDA under different pulling conditions were shown in Figure 5. It can be clearly seen that while the optical fiber in a designated area with two fixed points was pulled, the equally distributed strain of optical fiber was mainly concentrated between the areas of two fixed points; other areas of optical fiber did not get influenced. It can be indicated that the optical fiber sensing technique based on BOTDA can effectively reflect the mechanical deformation area.

The micrometer measured displacement values and the displacement values calculated by the optical fiber based on BOTDA are shown in Table 1. As observed, the error between the actual measurement with micrometer and the one calculated with optical fiber is very small. The average error is $0.6 \mathrm{~mm}$ and the maximum error is $0.98 \mathrm{~mm}$. The greatest error is mainly due to a smaller level of tension while the tension acting on the fixed point has not been fully transferred to the core. It will be avoided by improving the fixed point to reduce the slippage errors. The displacement curves for the data measured with micrometer and BOTDA-based optical fiber are shown in Figure 6. As observed, the absolute error between the displacements measured with micrometer and optical fiber decreased with the increasing tension level. The absolute error value is only $0.01 \mathrm{~mm}$ with the tension being $60 \mathrm{~mm}$. The relative error measured with micrometer and BOTDA-based optical fiber is shown in Figure 7. It can be found that the relative error reduced strongly with the increasing tension level. The displacement measured with BOTDA-based optical fiber is very close to the actual displacement value with higher deformation. These results 


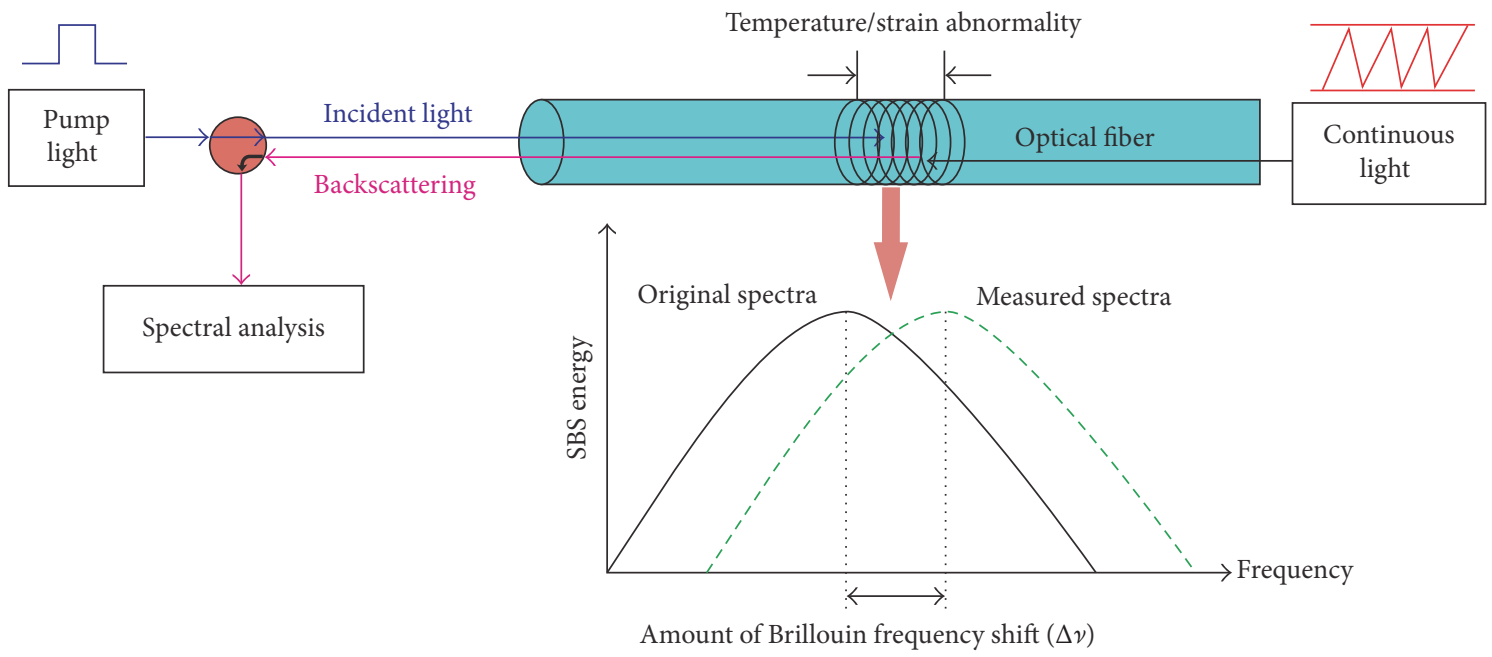

FIgURE 1: The basic principle of BOTDA.

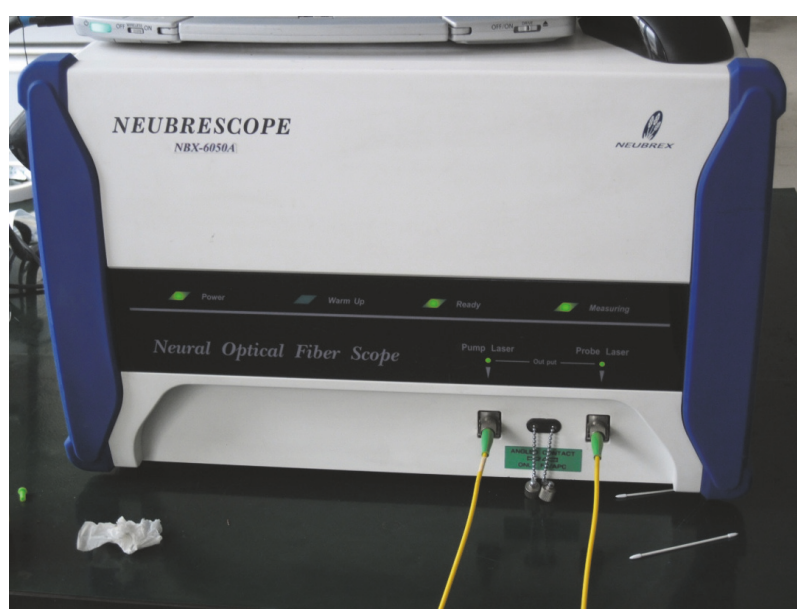

FIgURE 2: The NBX-6050A optical fiber strain demodulator.

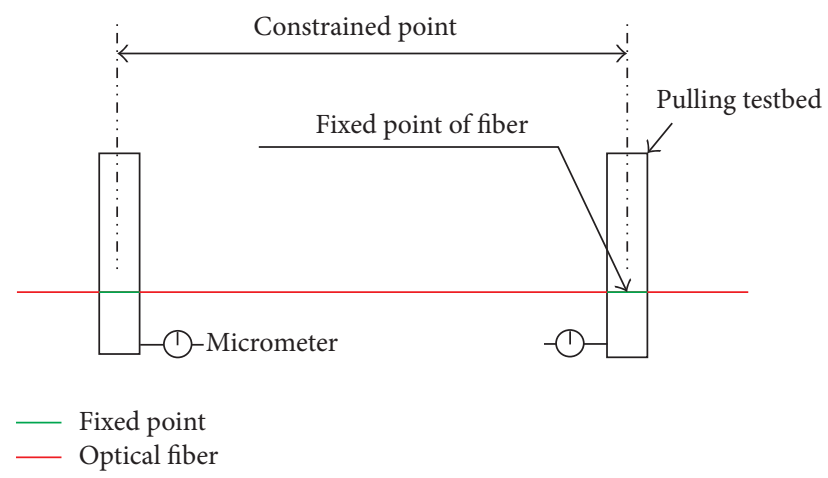

FIGURE 3: Schematic diagram of tensile stand.

indicated that the distributed optical fiber sensing technique based on BOTDA will meet the requirements of monitoring of ground deformations like ground fissure, land subsidence and slope deformation, and so on.

\section{Physical Model Test}

A physical model test on simulating ground deformation was carried out. The trench for this simulation has the size of $340 \mathrm{~cm}$ length, $75 \mathrm{~cm}$ width, and $80 \mathrm{~cm}$ depth. Three inflated airbags were buried in the trench to adjust the pressure. Fiber optical sensor and a ruler to measure the subsidence are also buried with the airbag. By reducing the pressure in the balloon at certain speed, the heterogeneous subsidence could be generated in the trench. The BOTDA fiber optical sensor measured the strain change during the pressure reduction process in the airbag. The schematic diagram of this experiment is shown in Figure 8.

4.1. Materials. Two optical fibers are used to monitor the strain variations. The first is the polyurethane optical fiber with diameter of $2 \mathrm{~mm}$. The second one is the modified version of the first with a $25 \mathrm{~mm}$ long quartz tube glued on the fiber at every $20 \mathrm{~cm}$ (see Figure 9).

The airbag used in the simulation is made of rubber and has a diameter of $25 \mathrm{~cm}$ and a length of $32 \mathrm{~cm}$. There is a valve to control the pressure and pressure change rate to simulate the ground deformation. A ruler with a protective aluminum tube is used to measure the ground subsidence. The soil has a composition of sand, clay, and water with a ratio of $9: 1: 1$.

\subsection{Simulation Procedures}

(1) Trenching. First, dig a $400 \mathrm{~cm}$ long, $75 \mathrm{~cm}$ wide, and $50 \mathrm{~cm}$ deep trench, and, then, in the middle, dig a $240 \mathrm{~cm}$ long, $30 \mathrm{~cm}$ deep ditch (see Figure 8).

(2) Flatten the bottom of the ditch using fine sand of thickness about $5 \mathrm{~cm}$.

(3) Install three balloons as shown in Figure 8. The longitudinal central positions of the balloons are $1.38 \mathrm{~m}$, $1.7 \mathrm{~m}$, and $2.02 \mathrm{~m}$, respectively.

(4) Install the rulers for subsidence measurement. The equipment of subsidence measurement is shown in 


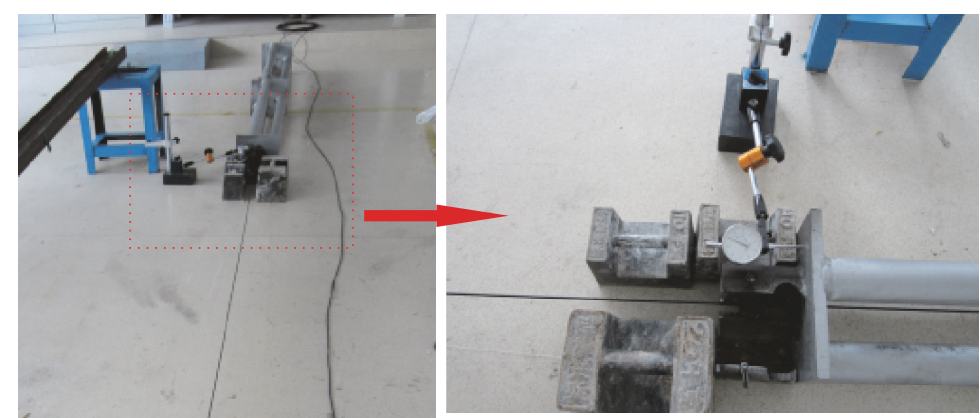

(b)

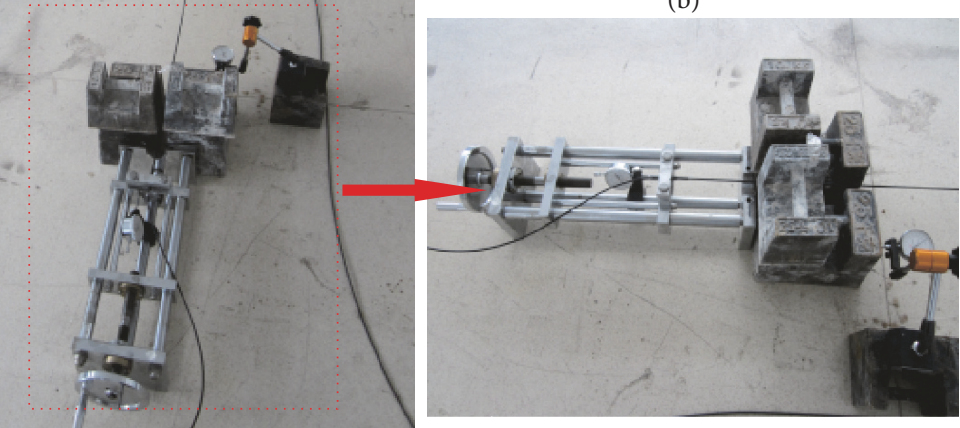

(a)

(c)

FIGURE 4: Testing apparatus of tensile test.

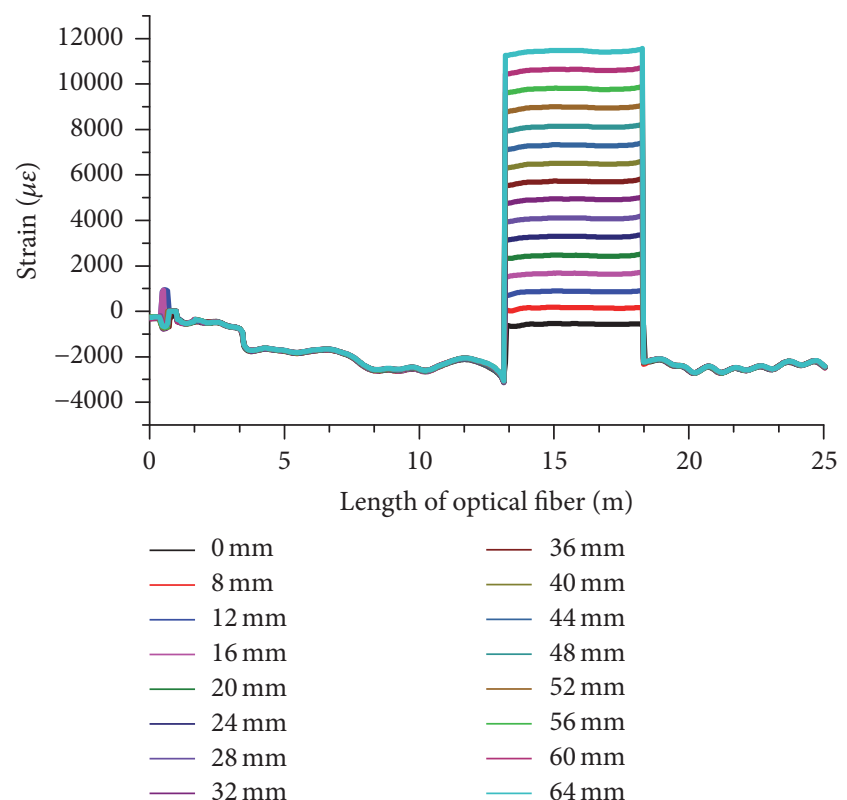

(a)

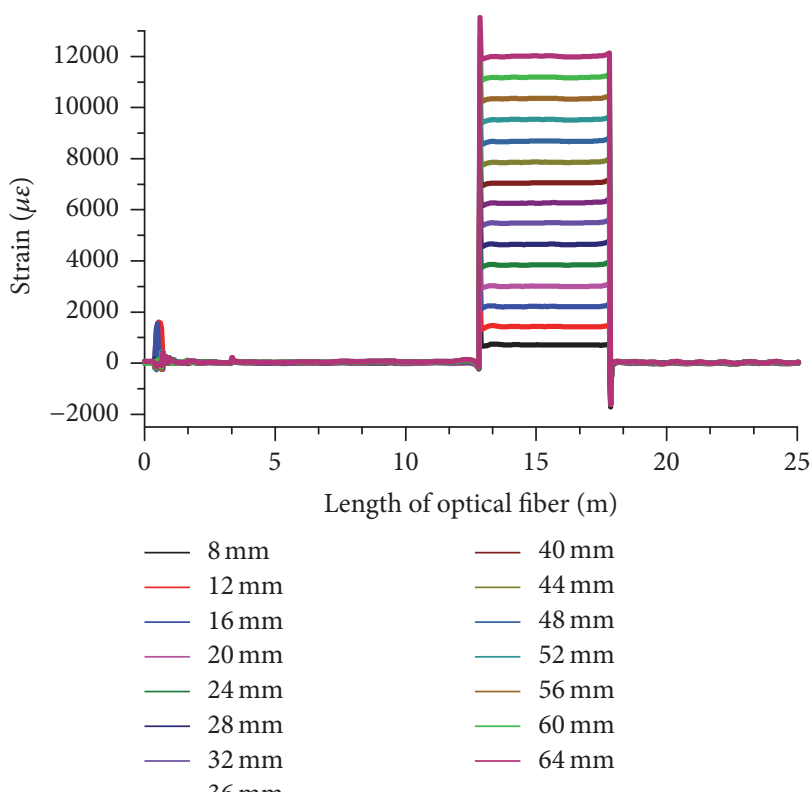

(b)

FIgURE 5: Optical fiber strain curves based on BOTDA under different pulling conditions.

Figure 10. The settlers are installed on the top of airbag with epoxy resin paste (see Figure 11) and marked with 1,2 , and 3 corresponding to the three airbags in Figure 8.

(5) Bury the airbag and install the fiber optical sensor at about $15 \mathrm{~cm}$ above the airbag. The distance between the two fibers is $5 \mathrm{~cm}$. The temperature compensation fiber is placed at the western side. The fiber is stretched with a predetermined force and then another $5 \mathrm{~cm}$ of soil is added, before subsidence ruler marked 4, 5, and 6 are installed. The soil is added to the top at the end. 
TABLE 1: The displacement values measured with micrometer and BOTDA.

\begin{tabular}{|c|c|c|c|c|c|}
\hline Displacement $(\mathrm{mm})$ & $\begin{array}{l}\text { Optical fiber strain } \\
(\mu \varepsilon)\end{array}$ & $\begin{array}{l}\text { Displacement with } \\
\text { micrometer }(\mathrm{mm})\end{array}$ & $\begin{array}{l}\text { Displacement with } \\
\text { BOTDA }(\mathrm{mm})\end{array}$ & Absolute error $(\mathrm{mm})$ & Relative error (\%) \\
\hline 4 & 708 & 4 & 3.54 & 0.46 & 11.5 \\
\hline 8 & 1425 & 8 & 7.13 & 0.87 & 10.875 \\
\hline 12 & 2210 & 12 & 11.05 & 0.95 & 7.917 \\
\hline 16 & 3003 & 16 & 15.02 & 0.98 & 6.125 \\
\hline 20 & 3838 & 20 & 19.19 & 0.81 & 4.05 \\
\hline 24 & 4643 & 24 & 23.22 & 0.78 & 3.25 \\
\hline 28 & 5481 & 28 & 27.41 & 0.59 & 2.107 \\
\hline 32 & 6264 & 32 & 31.32 & 0.68 & 2.125 \\
\hline 36 & 7045 & 36 & 35.23 & 0.77 & 2.139 \\
\hline 40 & 7854 & 40 & 39.27 & 0.73 & 1.825 \\
\hline 44 & 8673 & 44 & 43.37 & 0.63 & 1.432 \\
\hline 48 & 9523 & 48 & 47.62 & 0.38 & 0.792 \\
\hline 52 & 10343 & 52 & 51.72 & 0.28 & 0.538 \\
\hline 56 & 11176 & 56 & 55.88 & 0.12 & 0.214 \\
\hline 60 & 11997 & 60 & 59.99 & 0.01 & 0.017 \\
\hline
\end{tabular}

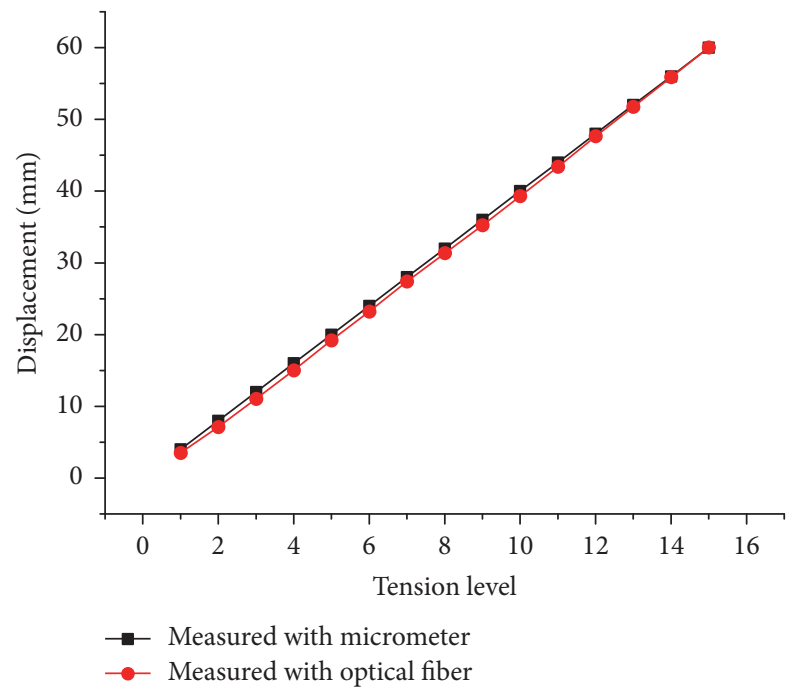

FIGURE 6: The displacement curves of strain measured with micrometer and optical fiber based on BOTDA.

(6) We will wait for 24 hours for the system to settle before the measurements.

4.3. Measurements. The baseline values are first collected. Heating is used to calibrate the optical fiber. Fiber strain showed a clear peak at the high temperature. We performed the measurements at the following nine situations.

Situation 1 (S1). Airbag 2 is flattened to normal pressure; 30 minutes waiting time is used before data collection.

Situation 2 (S2). Airbag 1 is flattened to normal pressure; 30 minutes waiting time is used before data collection.

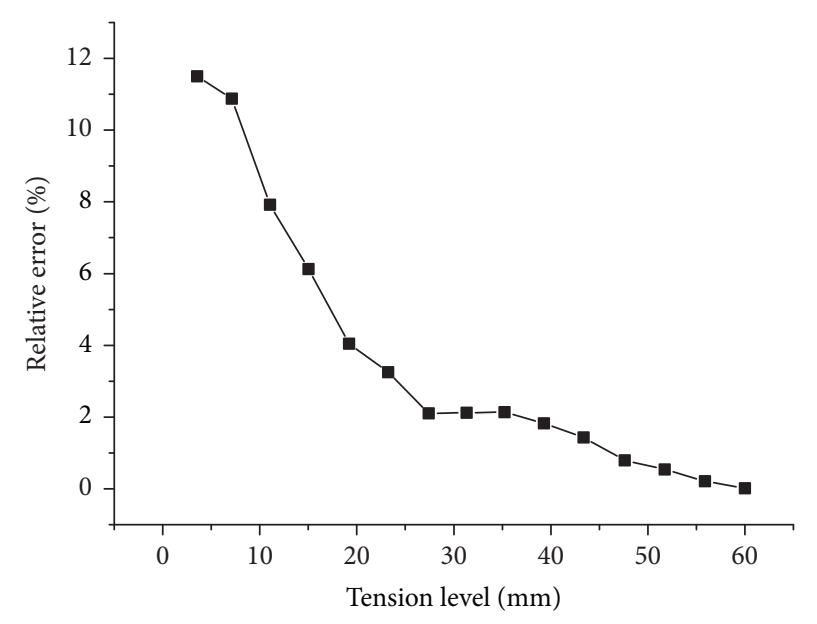

FIGURE 7: The relative error of strain measured with micrometer and optical fiber based on BOTDA.

Situation 3 (S3). Airbag 3 is flattened to normal pressure; 30 minutes waiting time is used before data collection.

Situation 4 (S4). Airbags 1-3 are flattened by opening the valve completely; 60 minutes waiting time is used before data collection.

Situations 5 and 6 (S5 and S6). Empty the air in airbag 2 using a pump, and collect the data after 30 and 60 minutes, respectively.

Situations 7, 8, and 9 (S7, S8, and S9). Empty the air in airbags 1 and 3, and collect the data after 30,60, and 120 minutes respectively. 


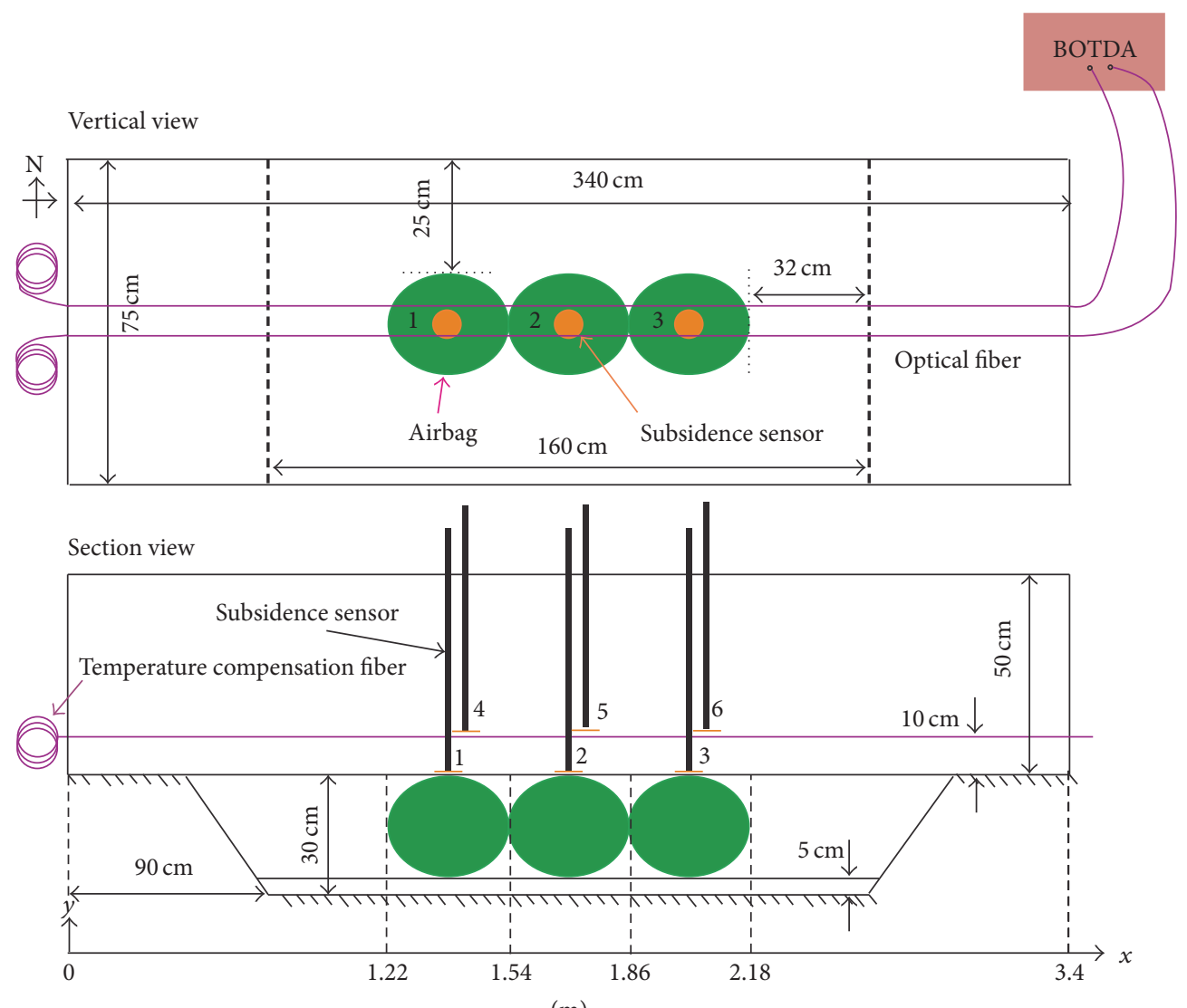

(m)

FIGURE 8: The schematic diagram of physical model test.

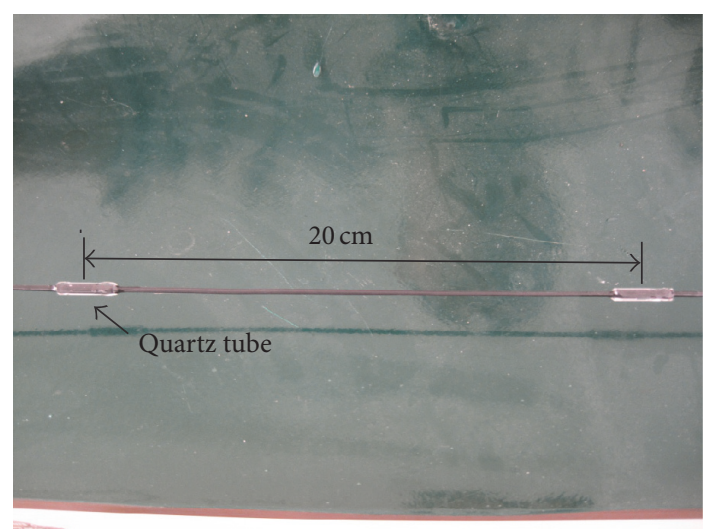

Figure 9: Optical fiber with quartz tube.

4.4. Results and Analysis. The subsidence is shown in Table 2. After baseline removal and temperature compensation, the fiber strain data is obtained. From Table 2 it can be observed that the subsidence increases as the airbag deflates. However, any significant change of subsidence at locations 4,5 , and 6 could not be observed. This is because of the fact that the soil sustained itself as the airbag got deflated. Some voids are created in the soil as the airbag deflates.

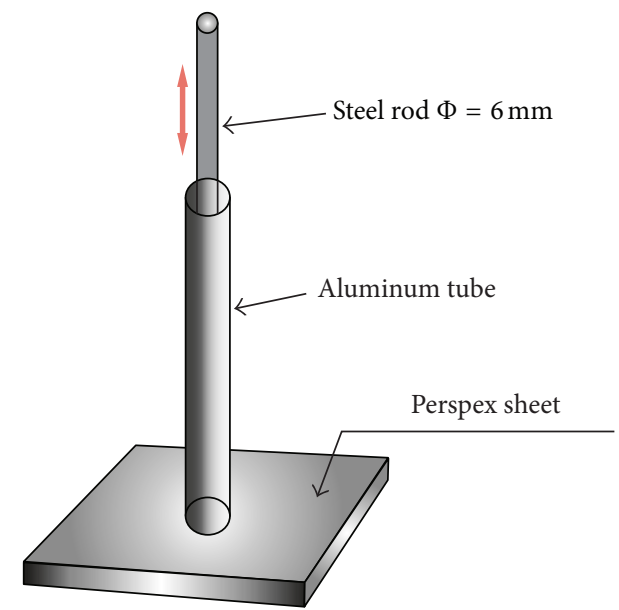

FIGURE 10: Subsidence measurement equipment.

In Situation 1, airbag 2 was deflated to normal pressure without pumping and the subsidence on top of airbag 2 is $30.34 \mathrm{~mm}$. There is no significant subsidence in all other locations. The strain distribution in this situation is shown in Figure 12. We can see the saddle shape of the strain centered at about $1.7 \mathrm{~m}$. In a region of about $40 \mathrm{~cm}$, the strain is compressive, and, immediately outside this region, the strain is tensile. 
TABLE 2: The subsidence data measured with settlers.

\begin{tabular}{lcccccc}
\hline \multirow{2}{*}{ Situations } & & \multicolumn{2}{c}{ Subsidence $(\mathrm{mm})$} \\
& Number 1 & Number 2 & Number 3 & Number 4 & Number 5 & Number 6 \\
\hline 1 & 0 & -30.34 & -32.02 & 0 & 0 & 0 \\
2 & -35.13 & -32.06 & -46.14 & 0 & 0 & 0 \\
3 & -36.8 & -32.09 & -46.21 & 0 & -0.05 & -0.06 \\
4 & -36.89 & -108.19 & -46.25 & 0 & -0.06 & 0 \\
5 & -36.93 & -109.08 & -46.41 & 0 & -0.09 & 0 \\
6 & -37.34 & -110.8 & -119.64 & 0 & -0.1 & 0 \\
7 & -107.85 & -110.84 & -119.65 & 0 & -0.1 & 0 \\
8 & -107.88 & -110.79 & -119.69 & 0 & -0.13 & 0 \\
9 & -107.84 & & & 0 & 0 \\
\hline
\end{tabular}

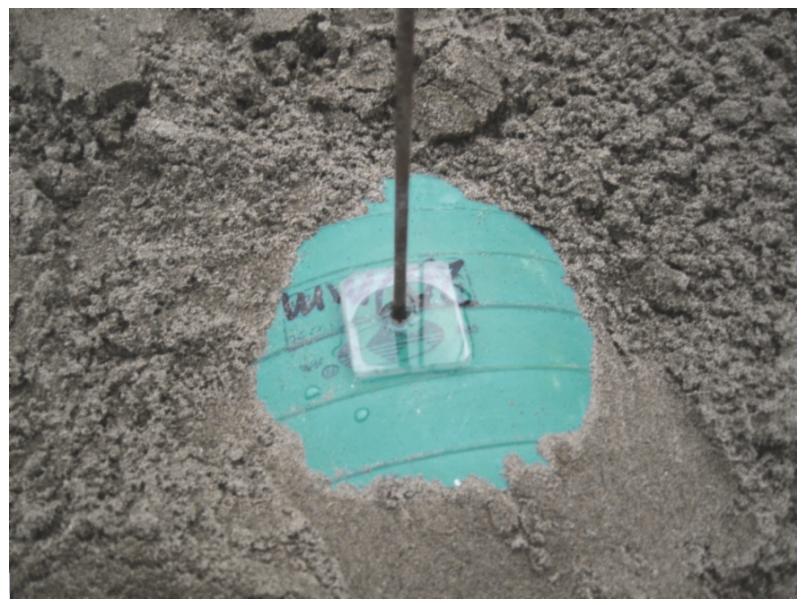

FIgURE 11: The settler on airbag.

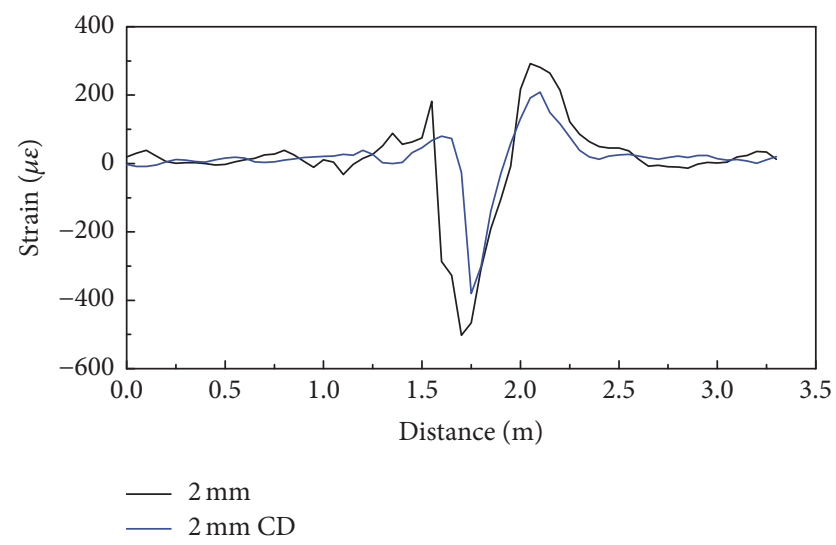

FIGURE 12: Strain distribution measured by two sensing optical fibers in Situation 1.

The compressive region is right at the top of airbag 2. The strain measured by the optical fiber is in agreement with the pressure change in this system. Because in this situation there is no significant subsidence at location 5 in the optical fiber layer, tensile strain outside the airbag region is reasonable. This tensile strain might cause fissure at the soil surface.
For Situations 1, 2, and 3, the strain distributions are shown in Figure 13. As airbags 1 and 3 deflate, the region with significant strain becomes larger, and the tensile strain outside increases. The amounts of subsidence at the three airbags are $-36.8 \mathrm{~mm},-32.06$, and $-46.14 \mathrm{~mm}$, respectively. Still there is no significant subsidence at the optical fiber layer. The deflation of airbags 1 and 3 merely increased the region of void. From Figure 13, it can be observed that the major strain occurs at the region $1.25-2.25 \mathrm{~m}$, where the three airbags are placed. The comparison between strains measured by the two different fibers indicates that the fiber without glass measures a more uniform strain (see Figure 13(b)). Because the fiber with glass makes a better coupling with the soil, it measures a more varied strain along the fiber.

The overall strain for Situations 1-9 measured by the fiber with glass is shown in Figure 14. As the airbags deflate, the tensile strain continues to increase. The amounts of subsidence at the three airbag tops are $-107.84 \mathrm{~mm},-110.79 \mathrm{~mm}$, and $-119.69 \mathrm{~mm}$, respectively. Still there is no significant subsidence at the optical fiber layer. The major strain occurs at the region right at the top of the three airbags.

From formula (1), the compressional displacement at the region $1.15-1.45 \mathrm{~m}$ could be calculated as $0.15 \mathrm{~mm}$. The tensional displacement at the region $1.45-1.65 \mathrm{~m}$ is $0.1 \mathrm{~mm}$. The compressional displacement at the region $1.65-1.8 \mathrm{~m}$ is $0.1 \mathrm{~mm}$, and the tensional displacement at the region $1.95-2.55 \mathrm{~m}$ is $0.6 \mathrm{~mm}$. The maximum tension happens at points $1.5 \mathrm{~m}$ and $2.2 \mathrm{~m}$. The depth of the fiber is $45 \mathrm{~cm}$ and the maximum displacement measured is $0.6 \mathrm{~mm}$. This displacement is not enough to cause ground fissure.

\section{Field Test}

5.1. Testing Program. A test site in Wuxi, China, was selected where ground fissure development due to subsidence is very common. The site layout is shown in Figure 15, where, in areas $\mathrm{A}$ and $\mathrm{B}$, the ground fissure development in the SWNE direction could be observed. Theoretically, the optimum monitoring direction should be perpendicular to the ground fissure direction. In this experiment, we installed the optical fiber in the 45-degree direction due to logistical constraint. The overall length of the monitored area from point $A$ to point $\mathrm{B}$ is $72 \mathrm{~m}$. 


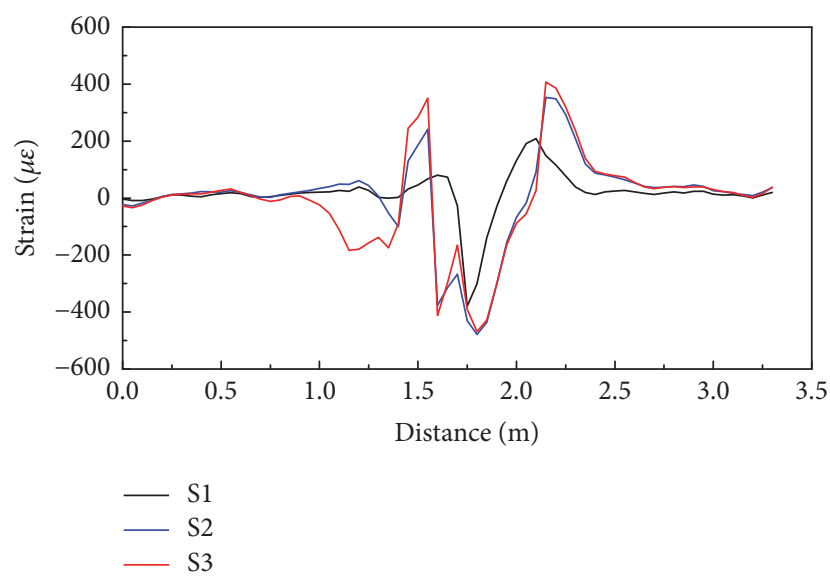

(a)

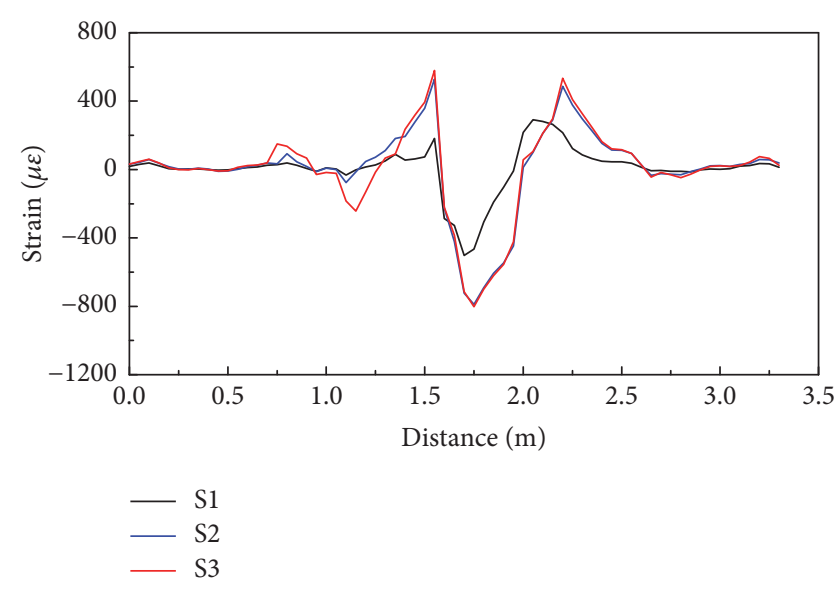

(b)

FiguRE 13: Strain distribution measured by two sensing optical fibers in Situations 1, 2, and 3. (a) Fiber with glass tube. (b) Fiber without glass tube.

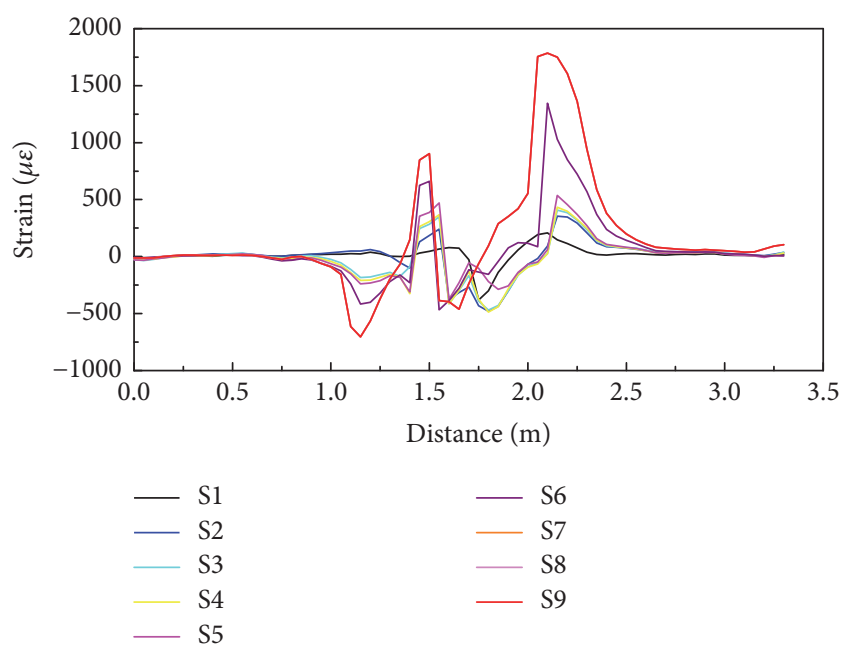

FIGURE 14: Strain distribution curve of changed diameter sensing optical fiber in Situations 1-9.

Because the earth is a porous medium, the ordinary optical fiber used in the communication industry can break easily in the burial process. Thus, we used a special optical fiber with high strength and optimum coupling with the earth deformation (see Figure 16). The maximum strain that can be measured is $15,000 \mu \varepsilon$. The optical fiber will break with deformation larger than $20,000 \mu \varepsilon$. Due to the fact that the deformation in the proximity of the ground fissure can be quite large, we installed the optical fiber as shown in Figure 17, where the optical fiber is fixed piecewise. This prevents the optical fiber from being broken or falling outside the measurement range. From the geological information, we have chosen the optical fiber piece of $200 \mathrm{~cm}$ long. This ensures the measurement range of $30 \mathrm{~mm}$ deformation.

The procedure for the optical fiber installation is shown in Figure 17. The first step is trenching as shown in Figure 17(a).

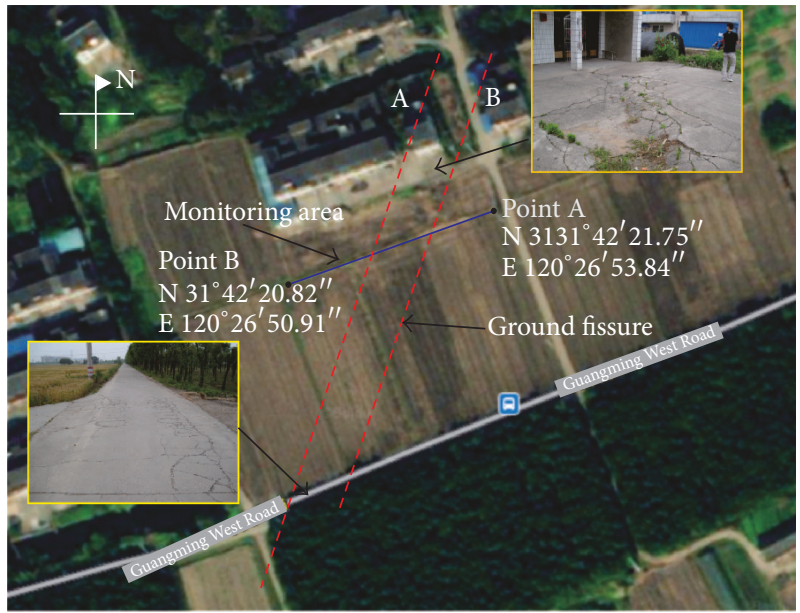

Figure 15: Field test site in Wuxi, China.

The trench is straight with the depth and width of $75 \mathrm{~cm}$ and $40 \mathrm{~cm}$, respectively. The second step is to spread about $10 \mathrm{~cm}$ thick fine sand at the bottom of the trench as shown in Figure 17(b). The third step is to anchor the optical fiber ends as shown in Figure 17(c). The anchor is pushed into the earth for $50 \mathrm{~cm}$ to ensure that it will follow the ground deformation. The monitoring optical fiber is protected by a tube from the surrounding earth pressure. The optical fiber end is glued to the anchor in step four (Figure 17(d)). The glue length is larger than $15 \mathrm{~cm}$ and the optical fiber is stretched to have an initial strain of $900 \mu \varepsilon-1200 \mu \varepsilon$. The monitoring optical fiber is buried by fine sand layer by layer (Figure 17(e)) and, finally, the fiber end is left on the ground and protected. To compensate the effect of seasonal temperature change, a free optical fiber in a tube is installed to bear the same temperature as the monitoring fiber. The Brillouin shift caused by temperature is removed from the measurement data. 


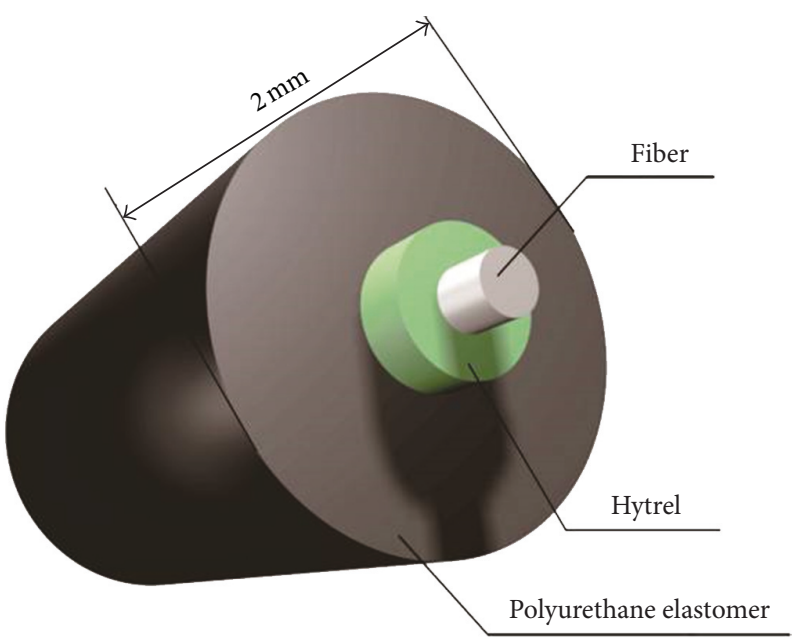

FIGURE 16: The structure of special optical fiber in field test.

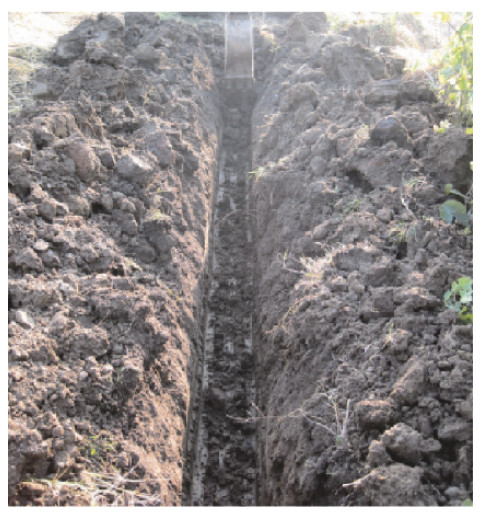

(a)

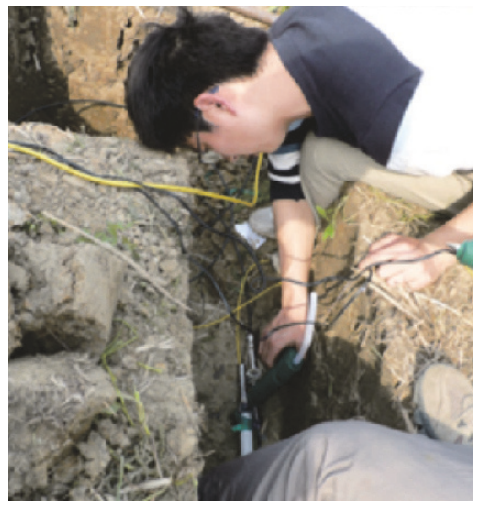

(d)

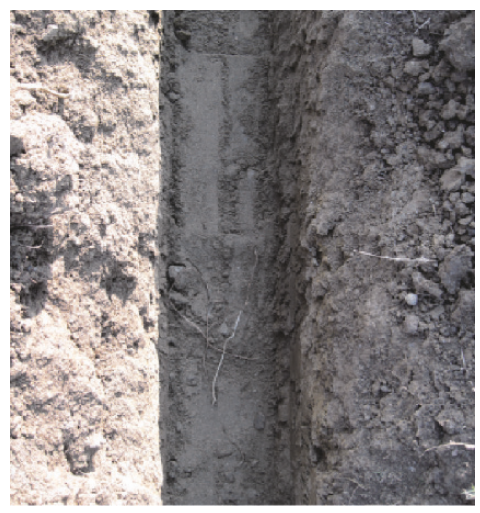

(b)

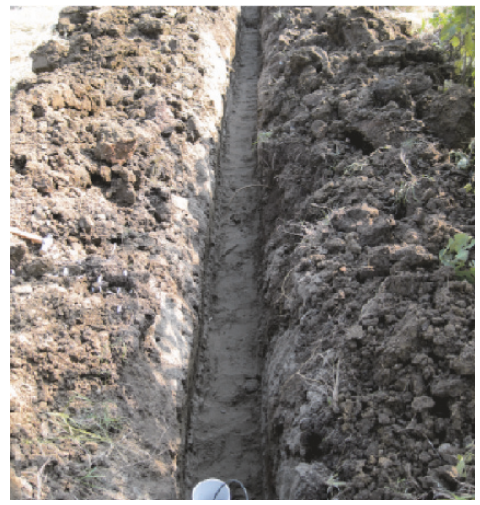

(e)

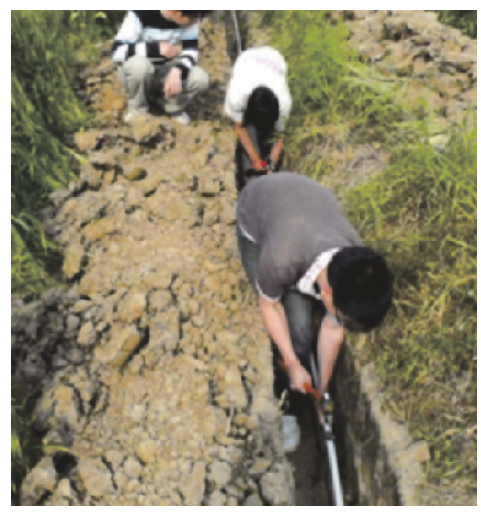

(c)

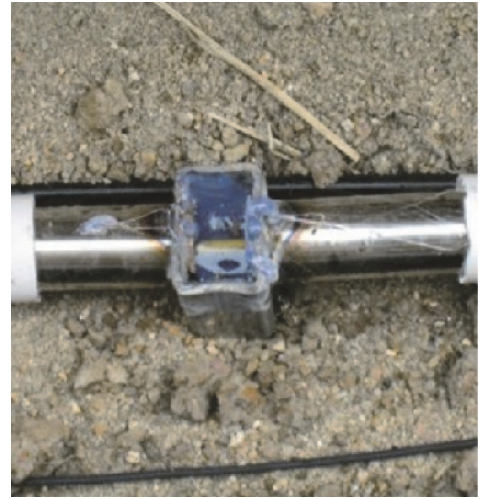

(f)

FIgURE 17: The procedure for the optical fiber installation.

5.2. Results and Analysis. Within a period from 20th June 2010 to 20th December 2015, measurements have been carried out nine times. The measurement dates are shown in Table 3.

After the temperature compensation and removal of the initial strain, the data are plotted in Figure 18. In the five-andhalf-year monitoring period, the strain shows two anomalies at distances $23 \mathrm{~m}$ and $55 \mathrm{~m}$ from point A. In Figure 19, we have marked these two locations as deformation areas $\mathrm{C}$ and $D$, respectively. The strains in areas $C$ and $D$ are both extensional. From points A22 m to A24 m, the accumulated deformation is $0.7 \mathrm{~mm}$, while, from points A54 m to A56 m, the accumulated deformation is $0.5 \mathrm{~mm}$. The separation between areas $C$ and $D$ is $32 \mathrm{~m}$ by length. The entire optical 
TABle 3: Measurement times.

\begin{tabular}{lccccccccc}
\hline Number & 1 & 2 & 3 & 4 & 5 & 6 & 7 & 8 & 9 \\
\hline Dates & $2010 / 06 / 20$ & $2010 / 09 / 20$ & $2011 / 01 / 14$ & $2011 / 05 / 20$ & $2011 / 07 / 23$ & $2012 / 12 / 26$ & $2013 / 12 / 16$ & $2014 / 12 / 22$ & $2015 / 12 / 20$ \\
\hline
\end{tabular}
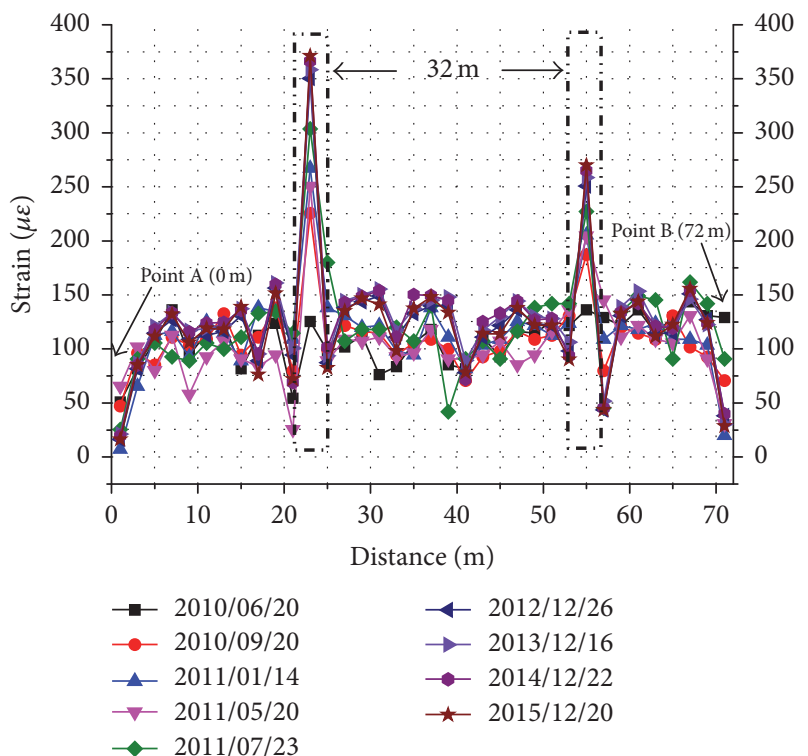

FIGURE 18: Strain variation of optical fiber in monitoring period.

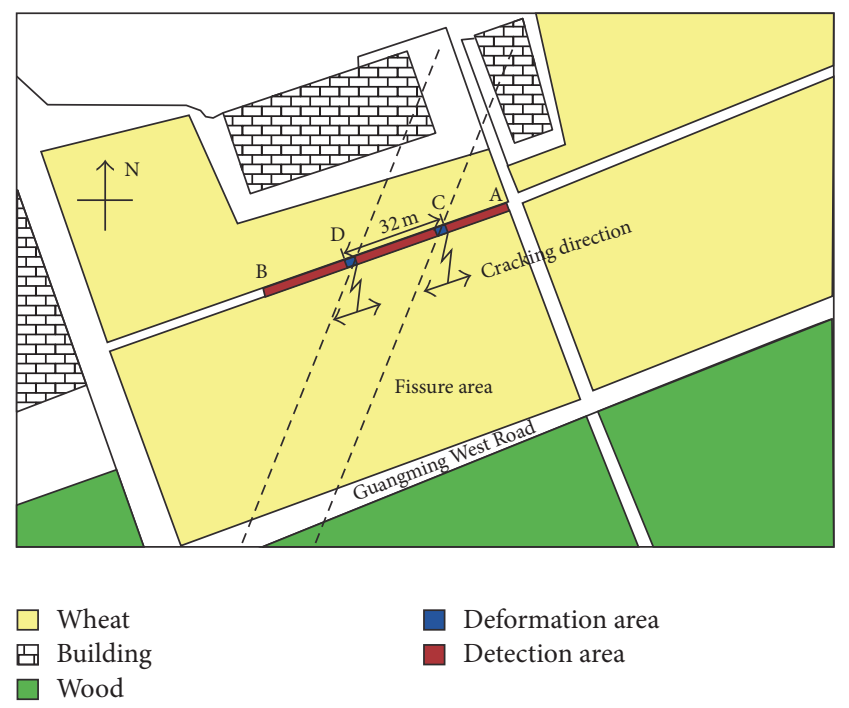

Figure 19: Location of $\mathrm{C}$ and $\mathrm{D}$ points in monitoring area.

cable is in the extensional state with strain varying from $7 \mu \varepsilon$ to $156 \mu \varepsilon$. During the whole time period, the entire optical cable is stretched by $11.3 \mathrm{~mm}$. This is due to the ground subsidence. On the ground, areas C and D mark the two edges of a developing ground fissure with $32 \mathrm{~m}$ width. The ground subsidence is not uniform. The east end (area C) shows larger strain. The strain variation with measurement time for $\mathrm{C}$ and $\mathrm{D}$ points is shown in Figure 20. As seen, the strain at both points $\mathrm{C}$ and $\mathrm{D}$ increased during the monitoring

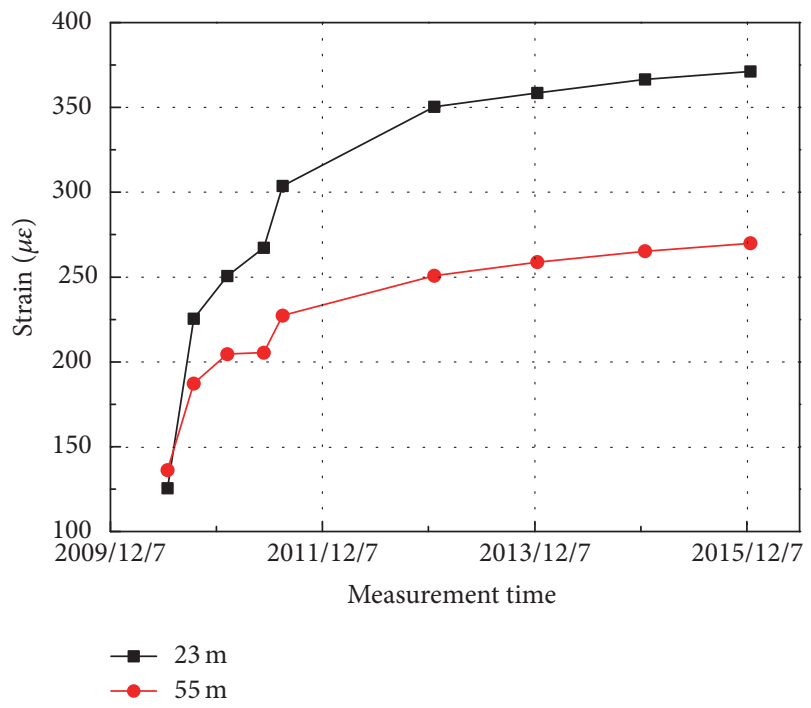

FIGURE 20: Strain variation with measurement time for C and D points.

period and the rate of increment becomes slower after about the end of year 2012. These monitoring results of ground deformation are in good agreement with the actual real-field situations. Limiting exploitation of groundwater and artificial groundwater recharge are being carried out to control the ground deformation from the end of 2012.

\section{Conclusions}

The technique for monitoring ground deformation was demonstrated using the BOTDA-based distributed optical fiber sensors. The following conclusions have been drawn based on the obtained results:

(1) BOTDA-based ground deformation monitoring is a very feasible technique, and the sensing optical fiber implantation method is quite effective.

(2) The laboratory calibration test indicated that the optical fiber sensors can monitor the stretching strain range accurately. The tensile displacement values measured by optical fiber sensor and micrometer gauge were almost in agreement and the testing error got reduced stronger with the bigger pulling stress.

(3) The physical model test showed that the distributed optical fiber sensors can measure the strain in soil during the ground deformation process, and the strain curve responded to the soil compression and tension regions clearly.

(4) Based on the deformation characteristics of ground fissure, the optimum monitoring direction should be perpendicular or skewed to ground fissure direction. 
The optical fibers with pieces of $200 \mathrm{~cm}$ long and $30 \mathrm{~mm}$ deformation range are used in the field test. The strain data showed anomalies at two locations of the developing ground fissure accurately. The strain data in the five-and-half-year monitoring period almost conform to the real-field development tendency of ground fissure.

\section{Conflicts of Interest}

The authors declare that there are no conflicts of interest regarding the publication of this paper.

\section{Acknowledgments}

This research was financially supported by Public Science and Technology Research Fund of Ministry of Land and Resources (Grant no. 201511055), Natural Science Foundation of Jiangsu Province, China (Grant nos. BK20141415 and BK20151011), and National Natural Science Foundation of China (Grant no. 41472241).

\section{References}

[1] Y. Ho, A. Huang, and J. Lee, "Development of a fibre Bragg grating sensored ground movement monitoring system," Measurement Science and Technology, vol. 17, no. 7, pp. 1733-1740, 2006.

[2] H.-F. Pei, J.-H. Yin, H.-H. Zhu, C.-Y. Hong, W. Jin, and D.-S. Xu, "Monitoring of lateral displacements of a slope using a series of special fibre Bragg grating-based in-place inclinometers," Measurement Science and Technology, vol. 23, no. 2, Article ID 025007, 2012.

[3] J. C. Blodgett, M. E. Ikehara, and G. E. Williams, "Monitoring land subsidence in sacramento valley, California, using GPS," Journal of Surveying Engineering, vol. 116, no. 2, pp. 112-130, 1990.

[4] L. Tosi, P. Teatini, L. Carbognin, and J. Frankenfield, "A new project to monitor land subsidence in the northern Venice coastland (Italy)," Environmental Geology, vol. 52, no. 5, pp. 889-898, 2007.

[5] P. Baldi, G. Casula, N. Cenni, F. Loddo, and A. Pesci, "GPSbased monitoring of land subsidence in the Po Plain (Northern Italy)," Earth and Planetary Science Letters, vol. 288, no. 1-2, pp. 204-212, 2009.

[6] J. H. Mao, W. L. Jin, Y. He, D. J. Cleland, and Y. Bai, "A novel method of embedding distributed optical fiber sensors for structural health monitoring," Smart Materials and Structures, vol. 20, no. 12, Article ID 125018, 2011.

[7] H. Mohamad, K. Soga, P. J. Bennett, R. J. Mair, and C. S. Lim, "Monitoring twin tunnel interaction using distributed optical fiber strain measurements," Journal of Geotechnical and Geoenvironmental Engineering, vol. 138, no. 8, pp. 957-967, 2012.

[8] H. Yoon, K. Song, C. Choi, H. Na, and J. Kim, "Real-time distributed strain monitoring of a railway bridge during train passage by using a distributed optical fiber sensor based on brillouin optical correlation domain analysis," Journal of Sensors, vol. 2016, Article ID 9137531, 10 pages, 2016.

[9] H. Su, M. Yang, K. Zhao, and Z. Wen, "Blind source separation model of earth-rock junctions in dike engineering based on distributed optical fiber sensing technology," Journal of Sensors, vol. 2015, Article ID 281538, 6 pages, 2015.
[10] Y. Lu, B. Shi, G. Q. Wei, S. E. Chen, and D. Zhang, "Application of a distributed optical fiber sensing technique in monitoring the stress of precast piles," Smart Materials and Structures, vol. 21, no. 11, Article ID 115011, 2012.

[11] C.-Y. Hong, Y.-F. Zhang, and L.-Q. Liu, "Application of distributed optical fiber sensor for monitoring the mechanical performance of a driven pile," Measurement: Journal of the International Measurement Confederation, vol. 88, pp. 186-193, 2016.

[12] B.-J. Wang, K. Li, B. Shi, and G.-Q. Wei, “Test on application of distributed fiber optic sensing technique into soil slope monitoring," Landslides, vol. 6, no. 1, pp. 61-68, 2009.

[13] Y. Ding, B. Shi, X. Bao, and J. Gao, "Jacket effect on strain measurement accuracy for distributed strain sensors based on Brillouin scattering," Optica Applicata, vol. 36, no. 1, pp. 57-67, 2006.

[14] C.-C. Zhang, H.-H. Zhu, B. Shi, and J.-K. She, "Interfacial characterization of soil-embedded optical fiber for ground deformation measurement," Smart Materials and Structures, vol. 23, no. 9, Article ID 095022, 2014. 


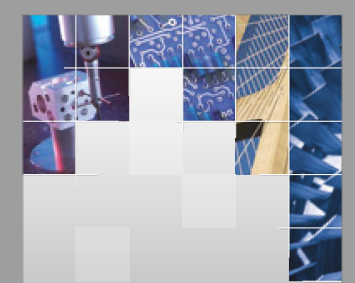

\section{Enfincering}
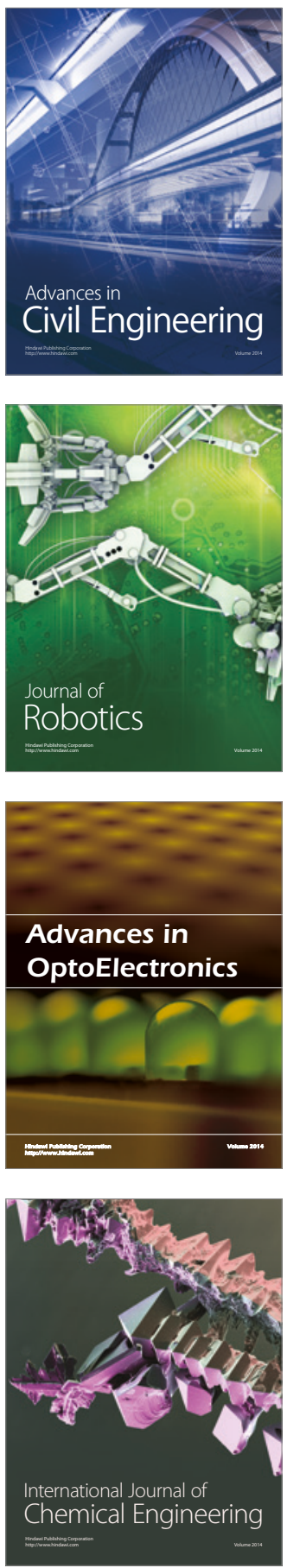

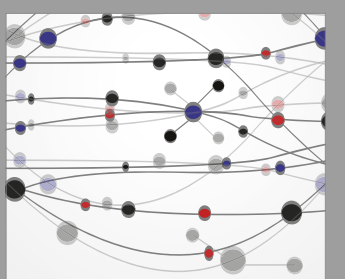

The Scientific World Journal

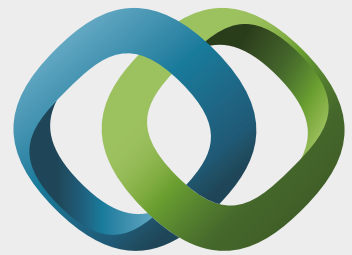

\section{Hindawi}

Submit your manuscripts at

https://www.hindawi.com
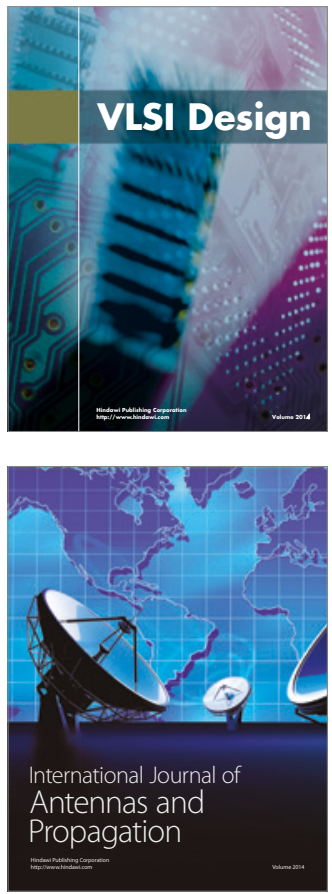

\section{Rotating}

Machinery
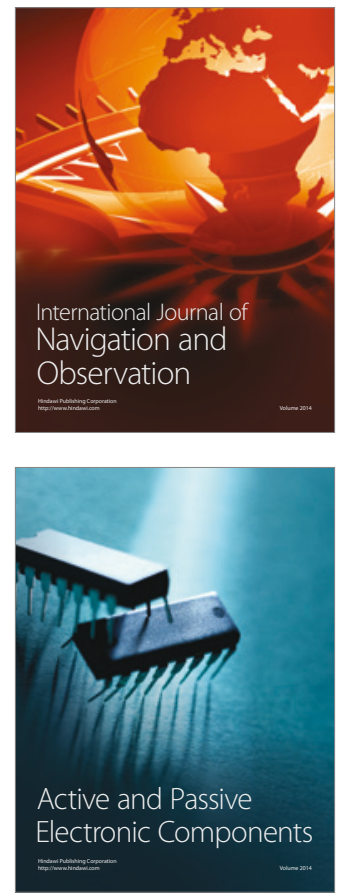
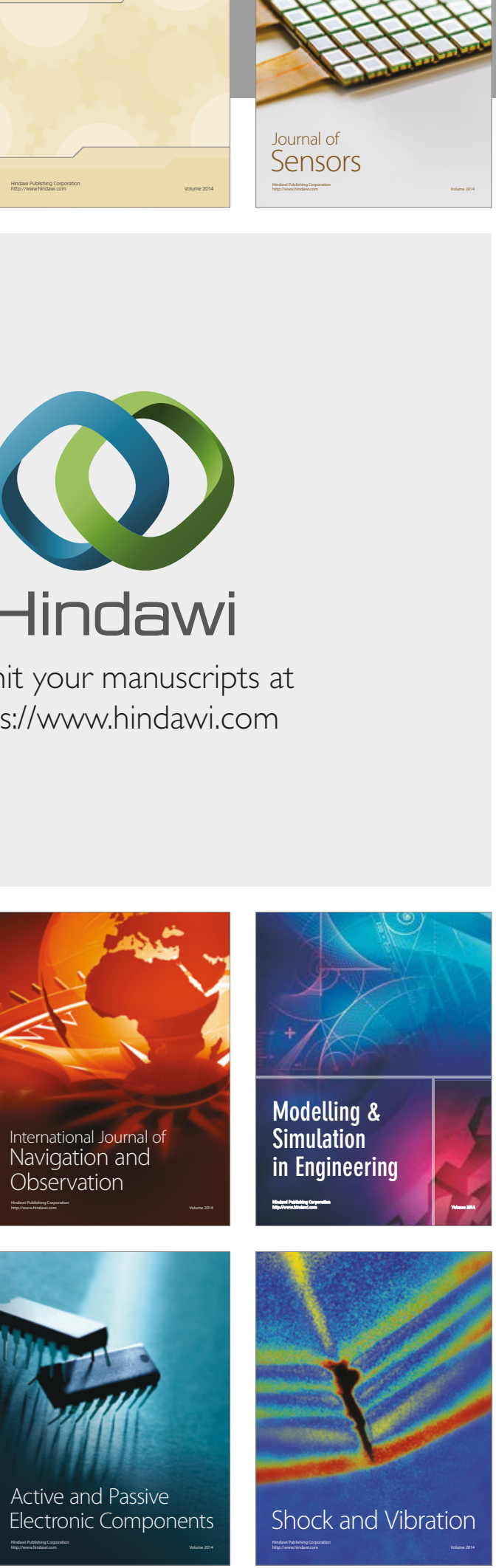
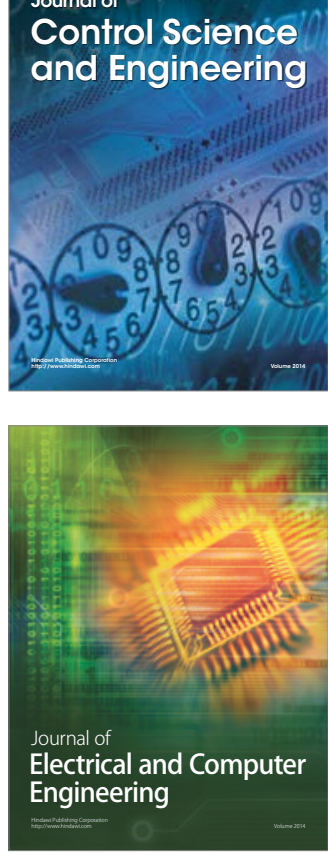

Distributed

Journal of

Control Science

and Engineering
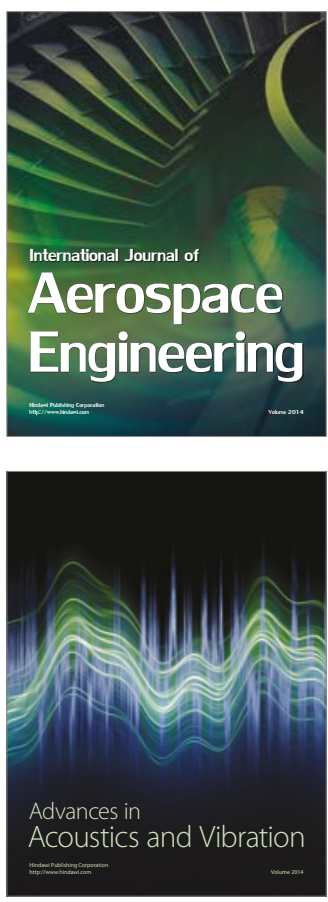

Sensor Networks 